\title{
Causal or Causal Relationship Between Oral Diseases and Systemic Amyloidosis - From Inflammation to Amyloidosis - A Trouble Connection
}

\author{
Murat İnanç Cengiz ${ }^{1}$ and Kuddusi Cengiz ${ }^{2}$ \\ 1Zonguldak Karaelmas University, Faculty of Dentistry, Department of Periodontology \\ ${ }^{2}$ Ondokuz Mayls University, Faculty of Medicine, Department of Nephrology
}

Turkey

\section{Introduction}

Although recent decades have provided significant advances in our understanding of the pathology and pathogenesis of AA amyloidosis, the mechanism and etiopathological factors promoting amyloidosis are largely unknown (Elimowa et al., 2009). Its pathogenesis is multifactorial, involving many variables such as primary structure of the precursor protein, acute-phase response, the presence of non-fibril protein, receptors, lipid metabolism and proteases (Röcken and Shakespeare, 2002). This pathogenetic process centers on the conversion of normally soluble proteins into insoluble fibrillar aggregates that disrupt tissue structure and cause disease. The organ distribution pattern of amyloid deposits and the resulting disease outcome depend on the origin and type of fibrillar protein deposited (Glenner, 1980; Kisilevski, 1992). Hence, amyloidosis is classified on the basis of the origin and biochemical composition of the precursor proteins that form the fibrillar deposits. The two most common forms of systemic amyloidosis are light-chain (AL) amyloidosis and reactive (AA or secondary) amyloidosis due to chronic inflammatory diseases. Beta-2 microglobulin amyloidosis is a common complication associated with long term hemodialysis. Hereditary systemic amyloidoses are a group of autosomal dominant disorders caused by mutations in the genes of several plasma proteins. In this section, we focus on the more common of these conditions, which are systemic AA amyloidosis, oral focal infections especially chronic periodontitis, and familial amyloidosis especially autoinflammatory diseases (Glenner, 1980; Kisilevski, 1992; Grateau et al., 2005).

Systemic AA amyloidosis, representing approximately 45 percent of generalized amyloidoses are inflammatory arthritis (Rheumatoid arthritis), chronic infections (Bronchiectasis, tuberculosis, chronic cutaneous infections, osteomyelitis), Immunodeficiency status, other conditions predisposing to chronic infections (Injected drug abuse, epidermolysis bullosa, paraplegia), Hereditary periodic fevers (Familial Mediterranean fever, Hyperimmunglobulin D syndrome, TNF receptor-associated periodic syndrome), Inflammatory bowel disease (Crohn's disease, ulcerative colitis), Neoplasia, Systemic vasculitis (Behçet's disease, systemic lupus erythematosis), others (Sarcoidosis). Reactive systemic AA amyloidosis is a 
potential complication of any disorder that gives rise to a sustained acute-phase response, and the list of chronic inflammatory, infective or neoplastic disorders that can underlie it is almost without limit (Lachmann and Hawkins, 2006).

Amyloid fibrils are derived from the cleavage fragments of the circulating acute-phase reactant (APR) serum amyloid A protein (SAA) (Pras et al., 1968). SAA is an apolipoprotein of high-density lipoprotein (HDL) which, like C-reactive protein (CRP), is synthesized by hepotocytes under the transcriptional regulation of cytokines including interleukin (IL)-1, IL-6, tumor necrosis factor (TNF)-alfa, beta and acute-phase reactants (APRs), either alone or combination, have been shown to affect SAA synthesis at the transcriptional level (Yamada, 1998). In the circulation, SAA levels may increase by 1000-fold in response to injury, infection, and inflammation, and thus SAA has properties resembling a classical positive APR. Because concentration of APRs may be correlated with the amount of damaged tissue, measurements of SAA are of value in the assessment of acivity and response to therapy during several inflammatory diseases (Malle and De Beer, 1996; Lachmann et al., 2005). Although AA amyloid can develop rapidly, the median latency between presentation with a chronic inflammatory disorder and clinically significant amyloidosis is almost two decades (Lachmann et al., 2005). The prognosis of AA amyloidosis depends on the degree of renal function and whether the underlying inflammatory disease can be suppressed. AA amyloidosis does not occur in the absence of an acute-phase response or without elevated SAA levels (Lachmann et al., 2007; Röcken and Shakespeare, 2002).

The theory of focal infection to explain various inflammatory disease was first suggested by Hippocrates and was widely propagated in the first three decades of the 20th Century. It was thought that foci of infection, which themselves might go unnoticed because of lack of symptoms, initiated the seeding of pathogenic microorganisms or their products to distant body sites.

Later, the concept of focal infection (i.e systemic effects from oral bacteria) is being changing and mostly relies on the correlation between chronic periodontitis and systemic diseases (Offenbacher, 1996; Scannapieco, 1998). At present it is generally agreed on that oral status is connected with systemic health, since poor oral health may occur concomitantly with more serious underlying diseases and/or it may predispose to other systemic diseases (Seymour et al, 2007). The pioneering approach of periodontal medicine has helped to renew attention on the theory of focal infection and the deepening of the relationship between chronic periodontitis and systemic health. Periodontal evaluations are normally not performed as part of medical assessment. Hence, periodontal diseases may be an overlooked source of inflammation in amyloid patients. However, the anagrommatic question of causal or causal association between infectious diseases and inflammatory changes is distant body sites was never satisfactorily addressed.

Various hypotheses, including common susceptibility, systemic inflammation, direct bacterial infection and cross-reactivity, or molecular mimicry, between bacterial antigens and self-antigens, have been postulated to explain these relationships. In this scenario, the association of periodontal disease with systemic diseases has set the stage for introducing the concept of periodontal medicine.

Obviously, cross-sectional clinical studies cannot determine whether periodontal disease is the cause of or is inconsequential to medical diseases, nor may longitudinal studies alone resolve the issue of causality. If periodontal disease and a given medical disease share etiological components, periodontal disease might appear earlier than the medical disease without having caused the disease, simply because periodontal disease develops faster than many medical diseases of complex multifactorial etiology. Although a number of studies 
have presented evidence of close relationships between periodontal and systemic diseases, the majority of findings are limited to epidemiological studies, while the etiological details remain unclear (Inaba and Amano,2010). Hence, periodontal diseases may be an overlooked source of inflammation in amyloid patients. Because of APRs that increase during the course of periodontal diseases is the cause of the etiopathogenesis of AA amyloidosis. Prior to, periodontal disease have not been investigated in the secondary amyloidosis with unknown etiology. Furthermore, in approximately 6 to $11.84 \%$ of causes of systemic AA amyloidosis no underlying disease can be found (Lachmann et al., 2007; Paydaş, 1999).

Clarification of the importance of oral focal infection requires controlled epidemiological studies and, probably, a better understanding of the etiology and the clinicopathological features of periodontal disease and medical diseases. Before adequate data are available, caution should be exercised in implicating periodontal disease or any other oral infection in the causation of major medical disorders like mortal systemic AA amyloidosis. Thus, the aim of this chapter is to emphasize that periodontal diseases may be considered as an etiological factor for amyloidosis. It is hereby suggested that periodontal evaluation should be performed as part of a routine medical assessment process. Preventing or treating periodontal disease might prevent or at least alleviate the progression of systemic AA amyloidosis. In terms of medical economics, understanding of the relationship between chronic periodontitis and systemic diseases has potential to change health policy, with ensuing economic benefits.

This chapter reviews the periodontal disease, auto-inflammatory syndromes relevant to oral health and suggested association of familial Mediterranean fever (FMF) and Behçet's disease

\section{Periodontal infection and systemic health}

Periodontal diseases are a group of bacterial inflammatory diseases of the supporting tissues of the teeth, in 1999, a classification of periodontal diseases has been proposed (Armitage, 1999). Periodontal diseases are common, initially bacteria-driven, chronic inflammatory condition leading to the formation of infected periodontal pockets, destruction of deep collagenous structures of the periodontium and alveolar bone, excessive mobility of the teeth and then their premature loss (Pihlstrom et al., 2005).

The cause of these common inflammatory conditions is the dental plaque. In $1 \mathrm{~mm}^{3}$ of dental plaque weighing approximately $1 \mathrm{mg}$. more than $10^{8}$ bacteria are present and over 300 species have been isolated and characterized in these deposits. Normally, the oral microbial community and the host immune response are in equilibrium which allows for periodontal health to the maintained, but pathology can occur when the balance is compromised for several causes:

a. modification of the environmental conditions of the site, caused by either bacterial interactions or accumulation of dental plaque;

b. reduction in the proportion of benefical bacteria, such as those producing inhibitory substances, caused by bacterial interactions or the use of systemic antibiotics; and

c. deficit of the host immune system.

The progression from gingivitis to periodontitis is characterized by periodontal pocket development, which favours further plaque accumulation and a shift in its qualitative composition (Pizzo et al., 2010). In July 1998, the American Academy of periodontology launched an effort to educate the public about new discoveries: infections in the mouth may play an important role in disorders involving other parts of the body (Scannapieco, 1998). At 
present it is generally agreed on that oral status is connected with systemic health, since poor oral health may occur concomitantly with more serious underlying diseases and/or it may predispose to other systemic diseases (Seymour et al., 2007). The pioneering approach of periodontal medicine has helped to renew attention on the theory of focal infection and the deepening of the relationship between chronic periodontitis and systemic health (Pizzo et al., 2010). The oral cavity is an open system exposed to the environment. It has been estimated that, in an individual with moderate to severe periodontitis, the total surface area of the inflammed periodontal pockets can range from 8 to $20 \mathrm{~cm}^{2}$ depending upon the number of teeth affected (Craig et al., 2007; Hujoel et al., 2001). Therefore, the large surface area of the aggregate periodontal lesion can potentially become a significant source of inflammation in individuals with moderate to severe periodontitis.

\section{Periodontal disease and systemic amyloidosis}

Periodontal pathogens, as well as their toxins, such as cytolitic enzymes and lypopolisaccharide (LPS) may have access to the blood stream through the compromised and/or ulcerated epithelium of the periodontal pocket. Moreover, within the inflammed gingival tissue a number of inflammatory mediators, such as tumor necrosis factor (TNF)alpha, interleukin (IL)-1 beta, prostaglandin $\mathrm{E}_{2}\left(\mathrm{PGE}_{2}\right)$, and gammainterferon are produced; these can enter the blood stream and contribute to the global inflammatory burden. Thus, the systemic exposure to periodontal pathogens, their toxins, and periodontal derived/ elicited inflammatory mediators may determine pathologic consequences in different organ or system. Three mechanisms by which periodontal infection may influence systemic health have been described.

1. metastatic infection caused by translocation of Gram-negative bacteria from the periodontal pocket to the bloodstream;

2. metastatic injury, such as vascular lesions from the effects of circulating microbial toxins and pro-inflammatory mediators;

3. metastatic inflammation due to the immunological response to the periodontal pathogens and their toxins (Li et al., 2000).

A cross-sectional study has demostrated that plasma levels of inflammatory markers such as $\mathrm{CRP}$, fibrinogen, interleukins and leucocyte counts increase in periodontitis patients when compared to periodontally healthy patients (Craig et al., 2003). Studies reported decrease in both IL-6 and CRP six months after initial periodontal therapy alone (D'Aiuto et al., 2004; 2005). Taken together, these studies suggest that not only can periodontitis elevate APRs and other systemic markers of inflammation but effective periodontal therapy may decrease acute-phase response values, as well.

Periodontal infections are polymicrobial and result from the accumulation of bacterial plaque and dental calculus at the gingival margin (Pihlstrom et al., 2005). These infections develop within several years and are often asymptomatic and painless, but may eventually lead to loss of teeth. It is widely regarded as one of the most common diseases worldwide, with a prevalence of $10 \%-15 \%$. A recent health examination survey from Finland involving 6300 participants revealed that up to $64 \%$ of the adult population had deepened gingival pockets associated with periodontitis, and nearly $20 \%$ had a severe form of this disease with pocket deeper than $6 \mathrm{~mm}$ (Knuuttila, 2004). One cubic millimeter of dental plaque contains about 100 milion bacteria and may serve as a persistent reservoir for potential pathogenic bacteria (Thoden et al., 1984). Subgingivally located bacteria and bacterial components and 
products, especially endotoxins, may easily enter the blood circulatory system via the infected and injured epithelium of deepened gingival pockets as well as after daily oral hygiene routines. Even gentle mastication leads to increased release of bacterial endotoxins into the peripheral blood (Geerts et al., 2002). Such bacterial release as well as systemic inflammation induced by local inflammation mediators, very likely occurs in periodontitis patients, not just transiently but also long-term. Continuous exposure to several periodontal pathogens fits well with the theory of the role of infections in systemic AA amyloidosis. Total pathogen burden, the number of pathogens, and endotoxemia, the concentration and activity of endotoxins, to which an individual has been exposed, may contribute to amyloidosis. The systemic immune response, genetic factors, and environmental factors also affects the risk of developing periodontitis (Agrawal et al., 2006) and systemic AA amyloidosis (Elimova and Kisilevski, 2009; Röcken and Shakespeare, 2002).

\section{Chronic periodontitis as a risk factor for systemic AA amyloidosis}

Systemic AA amyloidosis does not occur in the absence of acute-phase response or without SAA levels. The serum concentration of SAA closely reflects the activity of chronic inflammatory diseases, and persistently high concentration is a prerequisite for the development of AA amyloidosis (Lachmann et al., 2007; Röcken and Shakespeare, 2002). The natural history of AA amyloidosis is typically progressive, leading to organ failure and death among patients whose underlying inflammatory disease remained active. By contrast, there was regression of amyloid deposits, stabilisation or recovery of amyloidotic organ function, and excellent long-term survival among patients in whom the SAA concentration fell within the normal limit as a result of anti-inflammatory therapy (Röcken and Shakespeare,2002; Lachmann et al., 2007). However, in approximately 6 to $11.84 \%$ of causes of AA amyloidosis, no underlying disease could be found (Lachmann et al., 2007; Paydaş, 1997). The concept of focal infection (i.e systemic effects from oral bacteria) is being changing and mostly relies on the correlation between chronic periodontitis and systemic diseases (Offenbacher, 1996; Scannapieco, 1998; Seymour et al., 2007). Periodontal evaluations are normally not performed as part of a medical assessment. Hence, periodontal diseases may be an overlooked source of inflammation in amyloid patients. Prior to our study (Cengiz et al., $2010 \mathrm{a}, \mathrm{b}$ ), periodontal diseases have not been investigated in the secondary amyloidosis with unknown etiology. Moderate to severe periodontitis is prevalent in the general population and may be more prevalent in the systemic AA amyloid population (Cengiz et al., 2010 b). Periodontitis has been associated with increased markers of systemic inflammation. Therefore, periodontitis and AA amyloid populations may be a covert source of systemic inflammation that can be managed through effective periodontal therapy. Patients with chronic periodontal diseases have higher levels of SAA-the precursor protein of amyloid fiber in AA amyloidosis-than do the patients without periodontal disease (Glurich et al., 2002). Also, it has been reported that SAA and other APR levels were elevated in response to intravenous challenge with live porphyromonas gingivalis ( $P$. gingivalis), an important periodontal pathogen (Li et al., 2002).

In recent years, a study was published by Cengiz et al (2010b), analysing the etiological distribution of 112 patients with systemic AA amyloidosis showed that FMF (52.7\%), chronic inflammatory and neoplastic diseases (35.7\%) were the leading causes of systemic AA amyloidosis, while periodontal disease found in $11.6 \%$ of the patients under study. The prevalence of moderate to severe periodontitis was $47.5 \%$ in FMF patients, $72.5 \%$ in 
patients with known chronic inflammatory diseases, and $84.7 \%$ in patients with periodontal disease. Serum levels of APRs in amyloidosis patients were reduced significantly following nonsurgical periodontal therapy. They suggested that periodontitis may be an important occult source of chronic inflammation that increases the levels of acute-phase reactants in the patients and hence might affect the development of amyloidosis.

Periodontal disease shares several clinical and etiopathogenic characteristics with systemic AA amyloidosis. First, periodontal disease is a long-standing infectious or inflammatory disease and can cause a dramatic increase in the levels of systemic inflammation and periodontal treatment can result in the reduction in the levels of these markers. The increased serum APRs including SAA cause to the etiopathogenesis of systemic AA amyloidosis. Second, there is a close relationship between the severity of both diseases and serum APR levels. Third, the systemic immune response, genetic and environmental factors also affect the risk of developing periodontitis and systemic AA amyloidosis. Fourth, a limited number of experimental studies have shown that SAA and other APRs were elevated in response to an intravenous challenge with p.gingivalis. Fifth, treatment of periodontal disease reduces serum levels of inflammatory markers and underlying chronic inflammatory disease like systemic AA amyloidosis. Lastly, serum APRs that increase during the periodontal disease, are the cause to etiopathogenesis of systemic AA amyloidosis.

Collectively, these findings support the notion that periodontitis can elicit a potentially harmful systemic inflammatory response and may thus provide a potential risk factor for systemic AA amyloidosis and other diseases of inflammatory origin. Chronic periodontitis may be an additive factor to traditional etiologic factors for systemic AA amyloidosis as well as being primary etiological factor for systemic AA amyloidosis. Periodontal evaluation should be performed as part of a medical assessment.

Although the inflammation hypothesis provides a plausible and attractive explanation for the periodontitis-amyloidosis relationship, further research is needed to define the mechanisms linking the two diseases and how patients with periodontitis should best be managed to reduce their risk factor of systemic AA amyloidosis.

\section{Auto-inflammatory syndromes and amyloidosis}

The term "autoinflammatory disease" encompases an expanding group of inflammatory disorders defined as Mendelian genetic diseases of the innate immune system. This group is expanding considering the fact that diseases sharing strong similarities with this core group can be defined as auto-inflammatory. Familial Mediterranean fever (FMF) is the most frequent entity within this group of disorders which further consists of hyperimmunoglobulinaemia D and periodoic fever syndrome (HIDS), tumour necrosis factor receptor-associated periodic syndrome (TRAPS), cryopyrin-associated periodic syndrome (CAPS), Aphthous-like oral ulceration has been reported as one manifestation in several of the syndromes, including periodic fever, aphtous-stomatitis, pharyngitis, adenitis ((PFAPA), and pyogenic sterile arthritis, pyoderma gangrenosum acne (PAPA). Chronic jaw recurrent osteomyelitis has been recorded in chronic recurrent multifocal osteomyelitis (Juric, 2004; Girschic et al., 2007). Reactive (AA, secondary) amyloidosis is a severe complication of these diseases (Grateau et al., 2005). This is caused by deposition of fibrils that consist of the proteolytically cleaved acute-phase protein serum amyloid A (SAA). Several genetic and environmental factors modify the risk for systemic AA amyloidosis 
(van der Hilst et al., 2005; Scully and Hodgson 2008) Aphthous-like ulceration has been reported as one manifestation in some of the auto-inflammatory syndromes. Associations of other aphthous-like ulcers including Behçet's disease, Reiter's syndrome, Crohn's disease, systemic lupus erythematosus, and cyclic neutropenia support an immunopathological etiology (Livneh et al., 1996). Genetic, inflammatory and environmental factors predispose individuals to autoinflammtory and periodontal diseases. Periodontitis-induced autoinflammatory response also may play a role in development/severity of some autoinflammatory diseases and systemic AA amyloidosis via IL-1 gene alteration (Scully et al., 2008, Akman et al., 2008; Grateau and Duruöz, 2010). FMF and Behçet's disease are most frequent entities within this group of disorders.

\section{Relationship between periodontal parameters and Behçet's disease and systemic AA amyloidosis}

Behçet's disease (BD) is a chronic relapsing, systemic vasculitis of unknown etiology. Although several immunological abnormalities have been demonstrated in patients with $\mathrm{BD}$, the exact machanism of the inflammatory changes occuring remains to be elucidated (Sakane et al., 1999; Verity et al., 2003; Everekoğlu, 2005). The most probable hypothesis is that of an immunological driven inflammatory response set off by infectious agents in genetically predisposed individuals, a major pathologic process is vasculitis (Sakane et al., 1997; Alpsoy et al., 1998). Overexpression of proinflammatory cytokines from various cellular sources seem to be responsible for the enhanced inflammatory reaction in BD, and it may be associated with genetic susceptibility (Sakane et al., 1997; Gül, 2001).

In recent years, many studies emphasized the gene-environment interaction in the development of periodontitis and BD (Akman et al., 2008; Shirodaria et al., 2000; Gül 2001). Periodontitis-induced autoinflammatory response may also play a role in the development/severity of BD and periodontitis (Akman et al., 2008; Shirodaria et al., 2000; shimpuku et al., 2003).

Oral microbial flora have long been implicated in the pathogenesis, as BD starts mostly from the oral mucosal surface (Lehner 1997; Mumcu et al., 2004). In a recent study, Mumcu et al., (2006) have shown that oral health-related quality-of-life assessments were impaired in patients with BD and associated with disease activity and treatment modalities. Previous studies demonstrated that periodontal scores were higher in patients with BD than the healthy subject (Nakae et al., 1981; Celenligil-Nazliel et al., 1999; Mumcu et al., 2004; Akman et al., 2007; Karaçaylı et al., 2009; Arabacı et al.2009). Also, it has been speculated that BD might develop after the periodontitis and advenced periodontal disease may represent a risk factor for severe organ involvement (Akman et al., 2007).

Systemic AA amyloidosis has been important complication in the past, even in childhood onset patients. AA-type amyloid fibrils were found in all case studies (Akpolat et al., 2002). Oral ulcers are usually the first sign and the main classification criteria $(97-100 \%)$ in BD, causing an unpredictable course with remission and exacerbations. Genetic/environmental factors are implicated on the pathogenesis of amyloidosis. Serum amyloid A (SAA) polymorphism was found to be a risk factor for amyloidosis in BD (Utku et al., 2007). Furthermore, it has been demonstrated that long term periodontal follow-up and education of oral hygiene in patients with BD may help to prevent the development and/or progression of these diseases (Akman et al., 2008; Karaçaylı et al., 2009; Arabac1 et al., 2008). 


\section{Familial Mediterranean fever - Periodontal disease and systemic AA amyloidosis}

Familial Mediterranean fever (FMF) is an autosomal recessive inflammatory disease, which occurs worldwide but predominantly affects population from the Eastern Mediterranean Basin (Livneh et al., 2001). FMF is an autoinflammatory disease, characterized by recurrent attacks of fever and serosal inflammation, along with a very intense acute-phase response. The most important complication of FMF is systemic AA amyloidosis (Soher et al., 1967). Secondary amyloidosis also occurs in some FMF patients with chronic inflammatory conditions and chronic infections. The activation pattern of serum amyloid A (SAA) protein in the presence of inflammation was similar to that of CRP. Increased levels of CRP and SAA protein have been reported to be associated with increased FMF (Cengiz et al., 2009; De Beer et al., 1982; Akar et al., 2003), Periodontitis (Cengiz et al., 2009; Craig et al., 2003; D' Aiuto et al., 2005). and systemic AA amyloid (Cengiz et al., 2009; Lachmann et al., 2007) diseases activity and poor outcome in patients.

The genetic causes of amyloidosis have yet to be completely understood. It seems to be associated with M694V homozygous mutations of the FMF gene, MEFV, and with differences in SAA (Ben-Chetrit 2003; Aringer, 2004; Yiğit et al., 2008). Several investigators claimed that (Sidi et al., 2000, Cazeneuve et al., 1999, Mansour et al., 2001; Shohat et al., 1999 ) the M694V homozygote genotype was associated with the development of amyloidosis, whereas others (El-Shanti et al., 2006; Yalçınkaya et al., 2000) have not confirmed this finding.

It has been reported that APRs are generally elevated during acute attacks of FMF and return to normal upon clinical remission (Ben-Chetrit et al.1998). However, there are articles reporting that in some patients, even in those using colchicine regularly, the levels of APRs remain high in the intervals between acute attacks of FMF (Tunca et al., 1999), but the nature and source of this inflammation is unclear. Although changes in the salivary concentration of secretory immunoglobulin A and phagocytic activity of neutrophils in blood from the gingiva have been reported in patients with FMF (Akapion, 1998), the possibility that periodontal inflammation might contribute to increased APR levels in patients with FMF has not been investigated previously. Periodontitis is a local inflammatory process caused by bacteria and it may be associated with changes in the systemic inflammatory and immune responses (Slade et al., 2003; Craig et al., 2003). In fact, several reports have suggested that effective periodontal therapy may result in a decrease of the systemic markers of inflammation (D'Aiuto et al., 2004; D'Aiuto et al., 2005; Cengiz et al 2009).

Periodontitis and FMF have many potential pathogenic mechanisms in common. Both diseases have complex causes including genetic and gender predisposition, and might share many risk factors, such as age, education, smoking, social status and stress (Page, 1998; Touitou et al., 2007). Moreover, both diseases cause the release of the inflammatory markers. During the inflammatory response, local cells are stimulated to release APRs (Korkmaz et al., 2002; Ben-Chetrit et al., 1998; Tunca et al., 1999; Slade et al., 2003; D'Aiuto et al., 2005). Chlamydia pneumoniae has been found in patients with FMF and periodontitis (Altun et al., 2004; Paju et al., 2007). It is also known that chronic infection or inflammatory disease may cause systemic AA amyloidosis, even without obvious infection or inflammation (Cengiz, 2005; Nasr et al., 2006). Chronic inflammation and periodontal microbial burden may predispose patients with FMF to acute attacks of FMF or may be associated with 
amyloidosis in ways proposed for other infections, such as C. Pneumonia. Also, in approximately 6 to $11.86 \%$ of cases of systemic AA amyloidosis no underlying disease can be found (Lachmann et al., 2007; Paydaş, 1999).

Recently, a paper published by Cengiz et al., (2009) claimed that the prevalence of moderate to severe periodontitis in FMF patients with amyloidosis $(80.6 \%)$ was significantly greater than in FMF patients without amyloidosis (38\%) and controls $(20 \%)$. Serum levels of APRs in FMF patients were reduced significantly following nonsurgical periodontal therapy. In this study, it has been shown that periodontitis might be an important source of chronic inflammation or infection in FMF patients with and without amyloidosis.

The results of these studies confirm that periodontitis is highly prevalent in FMF patients, particularly in FMF patients with amyloidosis, and show a significant association between severe periodontitis and increased levels of APRs. Therefore, its diagnosis and management deserve a better interdisciplinary approach. Although most of the evidence regarding the relationship between periodontal disease and those systemic conditions is consistently supportive of this notion, more research is needed. Treating periodontitis might help to alleviate the disease burden in patients with FMF and systemic AA amyloidosis.

\section{References}

Agrawal, AA., Kapley, A., Yeltiwar, RK., Purohit, HJ. (2006) Assessment of single nucleotide polymorphism at IL-1 A+4845 and IL-1 B+3954 as genetic susceptibility test for chronic periodontitis in Maharashtrian ethnicity. J Periodontol 77 (9):1515-1521.

Akopian, GV. (1998) The local immune mechanisms of the involvement of the teeth and periodontium in periodic disease. Stomatolagiia (Mosk) 77: 4-7.

Akar, N., Hasipek, M., Akar, E., Ekim, M., Yalcınkaya, F., Çakar, N. (2003) Serum amyloid A1 and tumor necrosis factor-alpha allels in Turkish Familial Mediterranean Fever patients with and without amyloidosis. Amyloid 10: 12-16.

Akman, A., Kaçaroğlu, H., Dönmez, L., Bacanlı, A., Alpsoy, E. (2007) Relationship between periodontal findings and Behcet's disease: a controlled study. J Clin Periodontal 34: 485-491.

Akman, A., Çiçek-Ekinci, N., Kaçaroğlu, H., Yavuzer, U., Alpsoy, E., Yeğin, O. (2008) Relationship between periodontal findings and specific polymorphisms of interleukin- 1(alfa) and 1 (beta) in Turkish patients with Behçet's disease. Arch Dermatol Res 300: 19-26.

Akpolat, T., Akkoyunlu, M., Akpolat, I., Dilek, M., Odabaş, AR., Ozen, S. (2002) Renal Behçet's disease: a cumilative analysis. Semin Arthritis Rheum 31: 317-337.

Alpsoy, E., Yılmaz, E., Coskun, M., Savas, A.,Yegin, O. (1998) HLA antigens and linkage disequilibrium patterns in Turkish Behçet's patients. Journal of Dermatology 25: 158162.

Altun, S., Kasapçopur, O., Aslan, M., Karaarslan, S., Koksal, V., et al., (2004) Is there any relationship between Chlamydophila Pneumoniae infection and juvenile idiopathic arthritis? J Med Microbiol 53: 787-790.

Arabac1, T., Kara, C., Çiçek, Y. (2009) Relationship between periodontal parameters and Behçet's disease and evaluation of different treatments for oral recurrent aphthous stomatitis. J Periodontal Res 44: 718-725. 
Aringer, M. (2004) Periodic fever syndrome-a clinical overview. Acta Med Austriaca 31: 8-12.

Armitage, GC. (1999) Development of a classification system for periodontal diseases and conditions. Ann Periodontol 4: 1-6.

Ben-Chetrit, E. (2003) Familial Mediterranean Fever (FMF) and renal amyloidosisphenotype-genotype correlation, treatment and prognosis. J Nephrol 16: 431-434.

Celenligil-Nazlıel, H., Kansu, E.,Ebersole, J. (1999) Periodontal findings and systemic antibody responses to oral microorganisms in Behcet's disease. Journal of Periodontology 70: 1449-1456.

Cengiz, K. (2005) Uncommon etiology in renal amyloidosis. Acta Clin Belg 60: 109-113.

Cengiz, MI., Bağcı, H., Cengiz, S., Yiğit, S., Cengiz, K. (2009) Periodontal disease in patients with Familial Mediterrenean Fever: from inflammation to amyloidosis. J Periodontol Res 44(3): 354-361.

Cengiz, MI., Yayla, N., Cengiz, K., Bağc1, H., Taksın, E. (2010b) Interaction between periodontal disease and sytemic aa amyloidosis: from inflammation to amyloidosis. J. Periodontol [accepted, Ahead, of Print].

Cengiz, MI., Wang, HL., Yıldız, L. (2010a) Oral involvement in a case of AA amyloidosis: a case report. J Med Case Reports. 4(1): 200-206.

Craig, RG., Kotanko, P., Kamer, AR., Levin, NW. (2007) Periodontal disease-a modifiable source of systemic inflammation for the end-stage renal disease patient an hemodialysis therapy? Nephrol Dial Transplant 22: 312-315.

Craig, RG., Yip, JK., So, MK., Boylan, RJ., Socransky, SS., Hoffajee, AD. (2003) Relationship of destructive periodontal disease to the acute-phase response. J Periodontol 74: 1007-1016.

D'Aiuto, F., Nibali, L., Parker, M., Suvan, J., Tonetti, MS. (2005) Short-term effects of intensive periodontal therapy on serum inflammatory markers and cholesterol. J Dent Res 84: 296-273.

D'Aiuto, F., Parkar, M., Andreou, G., Suvan, J., Brett, PM., Ready, D., Tonetti, MS. (2004) Periodontitis and systemic inflammation: control of the local infection is associated with a reduction in serum inflammatory markers. J Dent Res 83: 156-160.

De Beer, FC., Mallya, RK., Fagan, EA., Lanham, JG., Hughes, GR. Pepys MB. (1982) Serum amyloid-A protein concentration in inflammatory diseases and its relationship to the incidence of reactive systemic AA-amyloidosis. Lancet 2: 231-234.

Elimova, E., Kisilevski, JB. (2009) Heparan sulfate promotes the aggregation of HBL associated serum amyloid A: evidence of a proamyloidogenic histidine molecular switch. FASEB J 23(10): 3436-3448.

El-Shanti, H., Majeed, AH., El-Khateeb, M. (2006) Familial Mediteranean Fever in Arabs. Lancet 367: 1016-1024.

Evereklioğlu, C. (2005) Current concepts in the etiology and treatment of Behçet's disease. Survival Ophthalmology 50: 297-350.

Falk, RH., Comenzo, RL., Skinner, M. (1997) The systemic amyloidosis. N Engl J Med 337: 898-909.

Geerts, SO., Nys, M., De, MP., Charpentier, J., Albert, A., Legrand, V., Rompen, EH. (2002) Systemic release of endotoxin-induced by gentle mastication: association with periodontitis severity. J Periodontol 73: 73-78. 
Girschick, HJ., Zimmer, C., Klaus, G., Darge, K., Dick, A., Morbach, H. (2007) Chronic recurrent multifocal osteomyelitis: what is it and how should it be treated? Nat Clin Pract Rheumatol 3: 733-738.

Gleneer, GG. (1980) Amyloid deposits and amyloidosis: the beta-fibrilloses (second of the two parts). N Eng J Med 302: 1333-1343.

Glurich, I., Grossi, S., Albini, B., Ho, A., Shah, R., Zeid, M., et al., (2002) Systemic inflammation in cardiovascular and periodontal disease: comparative study. Clin Diagn Lab Immunol 9: 425-432.

Grateau, G., Jeru, I., Rouaghe, S., Cazeneuve, C., Ravet, N., Duguesnoy, P., et al., (2005) Amyloidosis and auto-inflammatory syndromes. Curr Drug Target Inflamm Allergy. 4: 57-65.

Grateau, G., Duruöz, MT. (2010) Autoinflammatory Conditions: When to suspect? How to treat? Best Pract Res Clin Rheumatol 24(3) 401-411.

Gul, A. (2001) Behcet's disease: an update on the patogenesis. Clinical and Experimental Rheumatology 19: 6-12.

Hujoel, PP., White, BA., Garcia, RI., Listgarten, MA. (2001) The dentogingival epithelial surface area revisited. J Periodontol Res 36: 48-55.

Inaba, H., Amano, A. (2010) Roles of Oral bacteria in cardiovascular diseases from molecular mechanisms to clinical cases: Implication of periodontal diseases in development of systemic diseases. J Pharmacol Sci 113:103-109.

Jurik, AG. (2004) Chronic recurrent multifocal osteomyelitis. Semin Musculoskelet Radiol 8: 243-253.

Karaçaylı, U., Mumcu, G., Şimşek, I., Pay, S., Kose, O., Erdem, H., Direskenli, H., Günaydın, Y., Dinç, A. (2009) The close association between dental and periodontal treatments and oral ulcer in Behçet's disease: a prospective clinical study. J Oral Pathol Med 38: 410-415.

Kisilevski, R. (1992) Proteoglycans, glycosaminoglycans, amyloid enhancing factor, and amyloid deposition. J Entern Med 232:515-516.

Knuuttila, M. Hampaiden kiinnityskudossairaudet [periodontal diseases] in SuominenTaipale L, Nordblad A, Vehkalahti M, Aromaa a, editors. (2004) Suomalaisten aikuisten suunterveys [Oral health among the adult Finnish Population]. Terveys 2000-tutkimus [Health 2000-health examinationsurvey]. Finland: Helsinki: Publication of the National Public Health Institute; P 88-97.

Korkmaz, C., Özdoğan, H., Kasapçobur, O., Yazıc1, H. (2002) Acute phase response in Familial Mediterranean Fever. Ann Rheum Dis 61: 79-81.

Lachmann, HJ., Hawkins, PN. (2006) Systemic amyloidosis. Current Opinion in Pharmacology 6: $214-220$.

Lachmann, HJ., Goodman, HJB., Gallimore, J., Gilbertson, JA., Joshi, J., Pepys, MB., Hawkins, PN. (2005) Characteritic and clinical outcome of 340 patients with systemic AA amyloidosis. In Amyloid and Amyloidosis. Edited by Grateau G, Kyle RA, Skinner M, CRC Press 173-175.

Lachman, HJ., Goodman, HJB., Gilbertson, JA., Gallimore, RJ., Sabin, CA., Gillimore, JD., Hawkins, PN. (2007) Natural history and outcome in systemic amyloidosis. N Engl J Med 356: 2361-2371. 
Lehner, T. (1997) The role of heat shock protein, microbial and autoimmune agents in the aetiology of Behcet's disease. International Review of Immunology 14: 21-32.

Li, L., Massas, E., Batista, EL JR., Levine, RA., Amar, S. (2002) Porphyromonas gingivalis infection accelerates the progression of atherosclerosis in a heterozygous apolipoprotein E-deficient murine model. Circulation 105: 861-867.

Li, X., Kolltveit, KM., Tronstad, L., Olsen, I. (2000) Systemic diseases caused by oral infection. Clin Microbiol Rev 13: 547-558.

Livneh, A., Aksentijevich, I., Langevitz, P. Torosyan, Y., G-Shoham, N., et al., (2001) A single mutated MEFV allele in Israeli Patients suffering from Familial Mediterranean Fever and Behcet's disease (FMF-BD). Eur J Hum Genet 9: 191-196.

Malle, E., De Beer, FC. (1996) Human serum amyloid A (SAA) protein: a prominent acutephase reactant for clinical practice. Eur J Clin Invest 26: 427-435.

Mansour, I., Delague, V., Cazeneuve, C., Dode, C., Chouery, E., et al., (2001) Familial Mediterranean Fever in Labanon: Mutation Spectrum, evidence for cases in Maronites, Greek Orthodoxes. Greek Catholics, Syriacs and Chiites and for an assocation between amyloidosis and M694V and M6941 Mutations. Eur J Hum Genet 9: 51-55.

Mumcu, G., Ergun, T., Inanc, N., Fresko, I., Atalay, T., Hayran, O.,Direskeneli H. (2004) Oral health is impaired in Behcet's disease and is associated with disease severity. Rheumatology 43: 1028-1033.

Mumcu, G., Inanc, N., Ergun, T., Ikiz, K., Gunes, M., Islek, U., Yavuz, S., Sur, H., Atalay, T., Direskeneli, H. (2006) Oral health related quality of life is affected by disease activity in Behcet's disease. Oral Dis 12: 145-151.

Nakae, K., Agata, T., Maeda, K., Masuda, K., Hashimoto, T.,Inaba, G. (1981) Behcet's Disease Pathogenic Mechanism and Clinical Future: Case Control Studies on Behcet's Disease, 1st edn. Tokyo: University of Tokyo Press: 41-49.

Nasr, SH., Schwarz, R., D’Agoti, VD., Markowitz, GS. (2006) Paraplegia, proteinuria, and renal failure. Kidney Int 69: 412-415.

Offenbacher, S. (1996) Periodontal diseases: pathogenesis. Ann Periodontol 1: 821-828.

Page, RC. (1998) The pathobiology of periodontal diseases may affect systemic diseases: inversion of a paradigm. Ann Periodontal 3: 108-120.

Paju, S., Sinisalo, J., Pussinen, PJ., Valtonen, V., Nieminen, MS. (2007) Is periodontal infection behind the failure of antibiotics to prevent coronary events? Atherosclerosis 193: 193-195.

Paydas, S. (1999) Report on 59 patients with renal amyloidosis. Int Urol Nephrol 34(5): 619631.

Pihlstrom, BL., Michalowicz, BS., Johnson, NW. (2005) Periodontal diseases. Lancet 366: 1809-1820.

Pizzo, G., Guiglia, R., Russo, LL., Campisi, G. (2010) Dentistry and internal medicine: from the focal infection theory to the periodontal medicine concept. European Journal of Internal Medicine 21: 496-502.

Pras, M., Schubert, M., Zucker-Franklin, D., Rimon, A., Franklin, EC. (1968) The characterisation of soluble amyloid prepared in water. J Clin Invest 47: 924-933. 
Röcken, C., Shakespeare, A. (2002) Pathology, diagnosis and pathogenesis of AA amyloidosis Virchows Arch 440: 111-112.

Sakane, T., Takeno, M., Suzuki, N.,Inaba, G. (1999) Behçet's disease. Neww England Journal of Medicine 341: 1284-1291.

Scannapieco, FA. (1998) Position paper of the American Academy of periodontology: periodontal disease as a potential risk factor for systemic diseases. J Periodontal 69: 841-850.

Scully, C., Hodgson, TA. (2008) Recurrent oral ulcers; there is a trap. Oral Surg Oral Med Oral Pathol Oral Radiol Endod. 6: 845-852.

Scully, C., Hodgson, T., Lachmann, H. (2008) Auto-inflammatory syndrome and Oral Health. Oral Diseases 14: 690-699.

Seymour, GJ., Ford, PJ., Cullinan, MP., Leishman, S., Yamazaki, K. (2007) Relationship between periodontal infections and systemic disease. Clin Microbiol Infect 13 (Suppl 4): 3-10.

Shimpuku, H., Nosaka, Y., Kawamura, T., Tachi, Y., Shinohara, M., Ohura, K. (2003) Genetic polymorphisms of the interleukin-1 gene and early marginal bone loss around endosseous dental implants. Clin Oral Implants Res 14: 423-429.

Shirodaria, S., Smith, J., McKay, IJ., Kenet, CN., Hughes, FJ. (2000) polymorphism in the IL1A gene are correlated with levels of interleukin-1 alpha protein in gingival crevicular fluid of teeth with severe periodontal disease. J Dent Res 79: 1864-1869.

Sidi, G., Shinar, Y., Livneh, A., Langevitz P., Pras, M., Pras, E. (2000) Protracted febrile myalgia of Familial Mediterranean Fever: mutation analysis and clinical correlations. Scand J Rheumatol 29: 174-176.

Slade, GD., Ghezzi, EM., Heiss, G., Beck, JD., Riche, E., Offenbacher, S. (2003) Relationship between periodontal disease and c-reactive protein among adults in the atherosclerosis Risk in Communities study. Arch Intern Med 163:1172-1179.

Sohar, E., Gafni, J., Pras, M., Heller, H. (1967) Familial Mediterranean Fever. A survey of 470 cases and review of the literature. Am J Med 43: 227-253.

Thoden van Velzen, SK., Abraham-Inpijn, L., Moorer, WR. (1984) Plaque and systemic disease: a reappraisal of the focal infection concept. J Clin Periodontol 11: 209-220.

Touitou, I., Sarkisian, T., Medlej-Hashim, H., Tunca, M., Livneh, H., et al., (2007) Country as the primary risk factor for renal amyloidosis in Familial Mediterranean Fever. Arthritis Rheum 56: 1706-1712.

Tunca, M., Kırıkali, G., Soyturk. M., Akar, S., Pepys, MB., Hawkins, PN. (1999) Acute Phase response and evolution of Familial Mediterranean Fever. Lancet 353:1415.

Utku, U., Dilek, M., Akpolat, I., Bedir, A., Akpolat, T. (2007) SAA1 alpha/alpha alleles in Behçet's disease related amyloidosis. Clin Rheumatol 26: 927-929.

Van der Hilst, JCH., Simon, A., Drenth, JPH. (2005) Hereditary periodic fever and reactive amyloidosis. Clin Exp Med 5: 87-98.

Verity, DH., Wallace, GR., Vaughan, RW., Stanford, MR. (2003) Behçet's disease: from Hippocrates to the third millennium. British Journal of Ophthalmology 87: 1175-1183.

Yalçınkaya, F., Çakar, N., Mısırlığlu, M. et al., (2000) Genotype -phenotype correlation in a large group of Turkish patients with Familial Mediterranean Fever: evidence for mutation-independent amyloidosis. Rheumatology (Oxford) 39: 67-72. 
Yamada, T. (1999) Serum amyloid A (SAA): a concise review of biology, assay methods and clinical usefulness. Clin Chem Lab Med 37: 381-388.

Yiğit, S., Bağcı, H., Özkaya, O., Özdamar, K., Cengiz, K., Akpolat, T. (2008) MEFV mutations in patients with Familial Mediterranean Fever in Black Sea region of Turkey: Samsun experience. J Rheumatol 35: 106-113. 


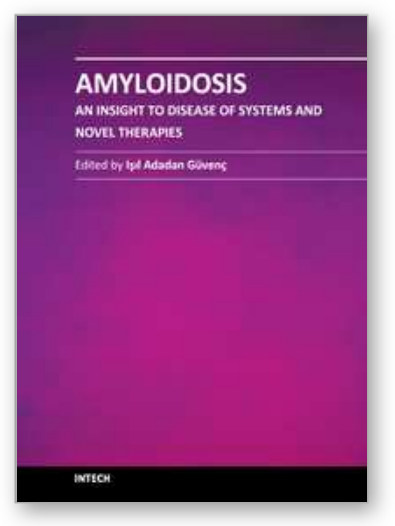

\author{
Amyloidosis - An Insight to Disease of Systems and Novel \\ Therapies \\ Edited by Dr. Işıl Adadan Güvenç
}

ISBN 978-953-307-795-6

Hard cover, 194 pages

Publisher InTech

Published online 16, November, 2011

Published in print edition November, 2011

Amyloidosis is a benign, slowly progressive condition characterized by the presence of extracellular fibrillar proteins in various organs and tissues. It has systemic or localized forms. Both systemic and localized amyloidosis have been a point of interest for many researchers and there have been a growing number of case reports in the literature for the last decade. The aim of this book is to help the reader become familiar with the presentation, diagnosis and treatment modalities of systemic and localized amyloidosis of specific organs or systems and also cover the latest advancements in therapy.

\title{
How to reference
}

In order to correctly reference this scholarly work, feel free to copy and paste the following:

Murat Inanç Cengiz and Kuddusi Cengiz (2011). Causal or Causal Relationship Between Oral Diseases and Systemic Amyloidosis - From Inflammation to Amyloidosis - A Trouble Connection, Amyloidosis - An Insight to Disease of Systems and Novel Therapies, Dr. Işıl Adadan Güvenç (Ed.), ISBN: 978-953-307-795-6, InTech, Available from: http://www.intechopen.com/books/amyloidosis-an-insight-to-disease-of-systems-and-noveltherapies/causal-or-causal-relationship-between-oral-diseases-and-systemic-amyloidosis-from-inflammationto-am

\section{INTECH}

open science | open minds

\section{InTech Europe}

University Campus STeP Ri

Slavka Krautzeka 83/A

51000 Rijeka, Croatia

Phone: +385 (51) 770447

Fax: +385 (51) 686166

www.intechopen.com

\section{InTech China}

Unit 405, Office Block, Hotel Equatorial Shanghai

No.65, Yan An Road (West), Shanghai, 200040, China

中国上海市延安西路65号上海国际贵都大饭店办公楼 405 单元

Phone: +86-21-62489820

Fax: $+86-21-62489821$ 
(C) 2011 The Author(s). Licensee IntechOpen. This is an open access article distributed under the terms of the Creative Commons Attribution 3.0 License, which permits unrestricted use, distribution, and reproduction in any medium, provided the original work is properly cited. 